\title{
MASSIGNON Geneviève (établie par), De bouche à oreille. Anthologie de contes populaires français
}

\section{Cécile Leguy}

\section{OpenEdition}

\section{Journals}

Édition électronique

URL : https://journals.openedition.org/clo/379

DOI : $10.4000 /$ clo.379

ISSN : 2266-1816

Éditeur

INALCO

\section{Édition imprimée}

Date de publication : 1 janvier 2008

Pagination : 472-474

ISBN : 978-2-85831-181-1

ISSN : 0396-891X

\section{Référence électronique}

Cécile Leguy, "MAssignon Geneviève (établie par), De bouche à oreille. Anthologie de contes populaires français », Cahiers de littérature orale [En ligne], 63-64 | 2008, mis en ligne le 23 février 2012, consulté le 07 juillet 2021. URL : http://journals.openedition.org/clo/379; DOI : https://doi.org/10.4000/clo.379

Ce document a été généré automatiquement le 7 juillet 2021.

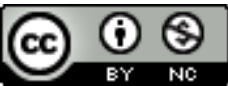

Cahiers de littérature orale est mis à disposition selon les termes de la Licence Creative Commons Attribution - Pas d'Utilisation Commerciale 4.0 International. 


\title{
MASSIGNON Geneviève (établie par), De bouche à oreille. Anthologie de contes populaires français
}

\author{
Cécile Leguy
}

\section{RÉFÉRENCE}

MASSIGNON Geneviève (établie par), De bouche à oreille. Anthologie de contes populaires français, Paris, José Corti, Collection Merveilleux n ${ }^{\circ} 30,2006,416$ p. (avec une postface de Nicole Belmont). ISBN 978-2-7143-0928-0

Dans ce recueil de contes, précédemment paru ${ }^{1}$ en anglais en 1968 aux États-Unis dans la collection Folktales of the World et devenu depuis lors un classique, Geneviève Massignon a rassemblé soixante-dix textes recueillis par elle-même (pour cinquantedeux d'entre eux) ou par d'autres dans certaines régions de France où la littérature orale gardait alors une certaine actualité. Les contes sont regroupés en quinze régions, formant autant de chapitres : Basse Bretagne, Haute Bretagne, Pays de Retz, Bas Poitou, Haut Poitou, Basse Marche, Angoumois et Ruffecois, Limousin, Massif Central, Forez, Franche-Comté, Dauphiné, Savoie, Pyrénées, Corse, les textes étant présentés en suivant l'ordre de la classification d'Aarne et Thompson dans chaque chapitre. Cette version française, publiée une première fois en 1983 chez Berger-Levrault avec un avant-propos de Marie-Louise Tenèze, est proposée ici complétée d'une éclairante postface de Nicole Belmont.

2 Ce qui fit la spécificité de cette anthologie lors de sa publication, c'est la volonté de Geneviève Massignon de s'en tenir aux contes recueillis lors d'enquêtes menées dans les années 1950-60, par elle-même et certains de ses collègues comme Pierre Nauton et Charles Joisten, pour en faire un recueil actuel de traditions orales, laissant de côté les textes notés par les folkloristes de la période comprise entre la guerre de 1870 et la première guerre mondiale, qualifiée d'« âge d'or du conte populaire français » par Paul 
Delarue. Ce recueil de contes est donc un témoignage sur le conte de tradition orale tel qu'il pouvait être entendu après la deuxième guerre mondiale dans certaines régions de France. En ce sens, il se démarque du corpus publié quelques années auparavant par Delarue $^{2}$ et Tenèze $(1957,1964)$.

3 Geneviève Massignon est d'abord une linguiste et dialectologue de terrain, circulant à bicyclette de village en village, de ferme en ferme, attentive à recueillir les textes dans leur contexte et à saisir en situation une tradition orale plus ou moins vivante selon les régions. Dans le cadre de ses enquêtes menées pour l'Atlas linguistique et ethnographique de l'Ouest, puis de celui de la Méditerranée, elle recueille ainsi, dans des formes dialectales de patois qu'elle connaît et qu'elle note scrupuleusement, des centaines de contes et de chansons grâce à des enquêtes intensives, plus précisément dans l'Ouest de la France et en Corse, régions de France où la tradition orale est encore très vivante. Sa fidélité aux données de l'enquête, saluée par Marie-Louise Tenèze dans son avantpropos donné ici dans un dossier complémentaire, lui fait publier des textes originaux, ne présentant pas forcément la fin attendue du récit, l'enquêtrice ne cherchant pas tant à donner «la bonne version" d'un conte qu'à rendre compte de la créativité des conteurs et de l'actualité de leur art.

4 C'est ce parti pris méthodologique que l'on retiendra des enquêtes de Geneviève Massignon et plus précisément de la publication de cette anthologie. En effet, comme le fait remarquer Nicole Belmont dans sa postface, si Geneviève Massignon n'a laissé que peu d'indications au sujet des principes méthodologiques qu'elle se donnait, le choix de ne retenir que des récits contemporains pour cette anthologie publiée dans la prestigieuse collection de Richard Mercer Dorson peut en lui-même être entendu comme un "manifeste »: il appelle à ne pas considérer le conte de tradition orale comme survivance d'un passé définitivement aboli, mais plutôt comme une modalité d'expression et de transmission qui évolue avec son temps, même si les conteurs et conteuses qu'elle rencontre sont bien souvent des personnes déjà âgées ou tenant d'un aïeul un récit mémorisé qu'elles n'ont plus si souvent l'occasion de dire.

5 À l'époque où Geneviève Massignon mène ses enquêtes, la littérature orale n'est guère à l'honneur et c'est en consacrant du temps au recueil de données sur les techniques, sur l'artisanat, sur le patois local qu'elle parvient à gagner la confiance de ses interlocuteurs qui, peu à peu, ne craignant plus d'apparaître comme trop "arriérés ", lui font entendre des chants, puis des contes, l'orientant alors vers ceux qui ont gardé la mémoire des récits d'autrefois, vers ceux qui savent encore conter. Les régions dans lesquelles elle mène ses enquêtes présentent par ailleurs un certain conservatisme, soit parce qu'on y parle une langue très différente du français, favorisant la préservation de modes d'expression locaux, soit parce qu'il s'agit de régions rurales demeurées en marge de l'industrialisation comme c'est le cas du bocage vendéen ou de la Brière où l'on a coutume de conter en pratiquant les travaux d'artisanat ordinaires.

6 Le corpus rassemblé ici nous offre un florilège de contes imagés, truffés de mots de patois et d'expressions populaires qui donnent à ce choix de textes une vivacité proche de l'oralité. «C'était un pauvre petit gars que sa mère ne pouvait pas souffrir... », « Il y avait une fois un homme et une femme qui avaient deux jolis petits-enfants, Jean et Jeannette, mais ils étaient pauvres comme des rats... ", "Un meunier avait trois drôles... ", ainsi commencent les contes, transformant notre lecture du livre en veillée à l'écoute d'une parole merveilleuse non encore oubliée en ces temps d'avant le renouveau du conte. 


\section{BIBLIOGRAPHIE}

BRU, Josiane, 2005, Le Delarue-Tenèze, catalogue raisonné des versions de France, Cahiers de littérature orale, $\mathrm{n}^{\circ}$ 57-58, p. 253-268.

DeLARUE, Paul, 1957, Le conte populaire français, Tome premier, Paris, Érasme [Nouvelle édition, Paris, Maisonneuve et Larose, 1976].

Delarue, Paul ( $†$ ), TENÈZE, Marie-Louise, 1964, Le conte populaire français, Tome deuxième, Paris, Maisonneuve et Larose.

\section{NOTES}

1. Geneviève Massignon, Folktales of France, Chicago, Chicago University Press, 1968 (Folktales of the World).

2. Quand Paul Delarue entame son entreprise de catalogage des contes français, il estime luimême « inventorier des reliques" (cf. Josiane Bru, 2005, p. 255-256). Ces deux premiers volumes du catalogue sont en effet principalement composés de versions recueillies avant 1914. 